\title{
Managing Expectations for Antibiotics When Seeing Patients With Upper Respiratory Tract Infections
}

Ann Fam Med 2014;12:iii. doi:10.1370/afm.1612.

The Annals of Family Medicine encourages readers to develop a learning community of those seeking to improve health care and health through enhanced primary care. You can participate by conducting a RADICAL journal club and sharing the results of your discussions in the Annals online discussion for the featured articles. RADICAL is an acronym for Read, Ask, Discuss, Inquire, Collaborate, Act, and Learn. The word radical also indicates the need to engage diverse participants in thinking critically about important issues affecting primary care and then acting on those discussions. ${ }^{1}$

\section{HOW IT WORKS}

In each issue, the Annals selects an article or articles and provides discussion tips and questions. We encourage you to take a RADICAL approach to these materials and to post a summary of your conversation in our online discussion. (Open the article online and click on "TRACK Comments: Submit a response.") You can find discussion questions and more information online at:www.AnnFamMed.org/AJC/.

\section{CURRENT SELECTION}

\section{Article for Discussion}

Mustafa M, Wood F, Butler CC, Elwyn G. Managing expectations of antibiotics for upper respiratory tract infections: a qualitative study. Ann Fam Med. 2014;12(1):29-36.

\section{Discussion Tips}

This study uses qualitative methods to try to tap into the wisdom of experienced family physicians for their strategies to reduce inappropriate antibiotic prescribing by managing expectations. The article presents an opportunity to develop subtlety in practice.

\section{Discussion Questions}

- What question is asked by this study and why does it matter?
- How does this study advance beyond previous research and clinical practice on this topic?

- How strong is the study design for answering the question?

- To what degree can the findings be accounted for by the following ${ }^{2}$ :

1. How participants were selected? (Did the authors achieve saturation? That is, did they sample until the point at which no new information was obtained from further sampling?)

2. How the data were collected?

3. Preconceptions on the part of the investigators?

4. How the findings were analyzed and interpreted?

5. The theoretical framework used to guide the investigation?

- What are the main study findings?

- How relevant is the study sample to you and your practice? Does it matter that the physicians are not a representative sample? What is your judgment about the transferability of the findings to your setting?

-What contextual factors are important for interpreting the findings?

- How might this study change your practice? Policy? Education? Research?

- Who are the constituencies for the findings, and how they might be engaged in interpreting or using the findings?

-What are the next steps in interpreting or applying the findings?

- What researchable questions remain?

\section{References}

1. Stange KC, Miller WL, McLellan LA, et al. Annals Journal Club: it's time to get RADICAL. Ann Fam Med. 2006;4(3):196-197. http:// annfammed.org/cgi/content/full/4/3/196.

2. Malterud K. Qualitative research: standards, challenges, and guidelines. Lancet. 2001;358(9280):483-488. 